\title{
Psychometric analysis of the short-form UCLA Loneliness Scale (ULS-8) in Taiwanese undergraduate students
}

\author{
Chia-huei $\mathrm{Wu}^{\mathrm{a}}$, Grace Yao ${ }^{\mathrm{b}, *}$ \\ ${ }^{a}$ Institute of Business and Management, National Chiao Tung University, Taiwan \\ ${ }^{\mathrm{b}}$ Department of Psychology, National Taiwan University, 1, Section 4, Roosevelt Road, Taipei, Taiwan
}

Received 20 August 2007; received in revised form 28 January 2008; accepted 7 February 2008

Available online 17 March 2008

\begin{abstract}
The main purpose of this study was to validate the short-form of the UCLA Loneliness Scale (ULS-8; Hays \& DiMatteo, 1987) in Taiwanese undergraduate students. A total of 130 undergraduate students participated in this study. Participants completed the ULS-8 in addition to measures of life satisfaction, social support, and adult attachment style. Result of confirmatory factor analysis supported the one-factor model of the ULS- 8 with adequate values of various fit indices, revealing that the 8 items of the scale were homogeneous for measuring loneliness. In addition, the ULS-8 had a negative relationship with life satisfaction, and social support; and a positive one with anxiety and avoidant attachment tendency. All the findings showed that the ULS-8 was an adequate short-form measure of loneliness.
\end{abstract}

(C) 2008 Elsevier Ltd. All rights reserved.

Keywords: Loneliness; UCLA Loneliness Scale; Psychometric analysis

\section{Introduction}

Research on the phenomenon of loneliness has advanced for the last 30 years (Peplau \& Perlman, 1982; Weiss, 1973). In the literature, loneliness plays an important role in investigating

\footnotetext{
${ }^{*}$ Corresponding author. Tel.: +88623366 3098; fax: +886223629909.

E-mail address: kaiping@ntu.edu.tw (G. Yao).
} 
the psychological process of human feelings and behaviors. Many studies indicated that loneliness has an influential effect on health (e.g., Cacioppo et al., 2002), social anxiety (e.g., Jones, Rose, \& Russell, 1990), psychopathology (e.g., Solomon, Waysman, \& Mikulincer, 1990), and even the behavior on the Internet (e.g., Moody, 2001; Morahan-Martin, 1999). However, when conducting empirical studies on loneliness, an adequate measure of loneliness is required. This measurement should capture the meaning of loneliness with a solid operational definition.

Among the empirical studies, the UCLA Loneliness Scale (ULS, Russell, Peplau, \& Ferguson, 1978; Revised ULS version, Russell, Peplau, \& Cutrona, 1980; ULS version 3, Russell, 1996) is the most commonly used self-report loneliness instrument (Russell, 1996). It was developed to assess subjective feelings of loneliness or social isolation. However, because the scale has 20 items, participants may feel burdened when answering the questionnaire. Hays and DiMatteo (1987) and Russell et al. (1980) developed short-forms of the UCLA Loneliness Scale. Both of the shortforms were derived from the Revised ULS version (R-ULS, Russell et al., 1980).

Russell et al. (1980) short-form scale, the ULS-4, has just 4 items. They were selected according to regression analysis, in which the 4 items were the best subset in predicting the self-labeling loneliness index consisting of 6 items, such as "During the past two weeks, how lonely have you felt?". Hays and DiMatteo (1987) short-form scale, the ULS-8, has 8 items. These items were selected according to an exploratory factor analysis result, in which 8 items had a substantial load on the first factor.

Hays and DiMatteo (1987) and Wilson, Cutts, Lees, Mapungwana, and Maunganidze (1992) had compared the two short-form scales with the R-ULS. Their results revealed that the ULS8 is a better substitute for the R-ULS than the ULS-4 in three aspects. First, the correlation between the ULS-8 and R-ULS $(r=0.91$, Hays \& DiMatteo, $1987 ; r=0.82$ to 0.87 , Wilson et al., 1992) was higher than the correlation between the ULS-4 and R-ULS $(r=0.88$, Hays \& DiMatteo, $1987 ; r=0.69$ to 0.74 , Wilson et al., 1992). Second, the internal reliability (coefficient $\alpha$ ) of the ULS-8 $(\alpha=0.84$, Hays \& DiMatteo, $1987 ; r=0.56-0.60$, Wilson et al., 1992) was higher than that of the ULS-4 ( $\alpha=0.63$, Hays \& DiMatteo, $1987 ; r=0.31-0.45$, Wilson et al., 1992). Third, the correlations between the ULS-8 and other related measures, such as social anxiety, alienation, satisfaction with friends, sex life, family, and self, were similar to the correlations between the R-ULS and these measures, but higher than those of the ULS-4 and these measures (Hays \& DiMatteo, 1987). In addition, Wiseman, Guttfreund, and Lurie (1995) showed that the ULS-8 was positively correlated with depression. These findings were consistent with the theoretical relations of loneliness. Thus, the existing findings suggested that ULS- 8 was a better substitute for the R-ULS than the ULS-4.

The purpose of this study was to validate the ULS-8 with a sample of Chinese individuals in Taiwan, because no short-form version of the ULS was validated on Chinese samples. In addition, the most important reason was that a short-form scale can facilitate researchers to conduct a large-scale survey using only several items to measure loneliness. For example, Academia Sinica conducts the Taiwan Social Change Survey (TSCS) every year. The TSCS is a national survey, which contains many questionnaires assessing various constructs within a specific topic of the year. In order to assess as many constructs as possible, items in the full version of a standard measurement cannot all be included in the survey. Researchers in the survey committee have to abbreviate the length of questionnaires. As a result, validating the ULS-8 on Chinese people makes a practical contribution in a large-scale survey when loneliness is one of target constructs. 
In this study, the factor structure of ULS-8 was examined first using confirmatory factor analysis. Second, correlation analyses were conducted to examine whether the ULS-8 has hypothetical relations with subjective well-being, social support, and adult attachment for investigating the validity of the ULS-8. These three constructs were selected because of their reliable relations with loneliness in the existing literature. Regarding subjective well-being, many studies indicated that people with higher loneliness would have lower subjective well-being (e.g., DiTommaso, Brannen, \& Best, 2004; Goodwin, Cook, \& Yung, 2001; Kahn, Hessling, \& Russell, 2003; Neto, 1995). Studies also showed that loneliness was negatively correlated with social support (e.g., Davis, Morris, \& Kraus, 1998; Jackson, Fritch, Nagasaka, \& Gunderson, 2002; Kahn et al., 2003; Russell, 1996). Finally, according to adult attachment studies, insecure attachment tendency, such as anxiety and avoidant attachment, had a positive relationship with loneliness (e.g., DiTommaso et al., 2004; DiTommaso, Brannen-McNulty, Ross, \& Burgess, 2003; Florian, Mikulincer, \& Bucholtz, 1995; Man \& Hamid, 1998). Therefore, it is expected that the ULS-8 has negative relations with subjective well-being, and social support, and has positive relations with insecure attachment tendency.

\section{Method}

\subsection{Participants and procedure}

A total of 130 National Taiwan University (NTU) undergraduate students participated in this study to get extra credits in the course of introductory psychology. Fifty-eight of the subjects were male (Mean age $=20.20, \mathrm{SD}=1.49$ ) and 72 of the subjects were female (Mean age $=20.24$, $\mathrm{SD}=2.97$ ). Information of this study was posted on the bulletin for psychological studies. Participants who were interested in this study signed their names on a sheet which indicated the time and place for participation. Regarding test administration, researchers first gave instructions to explain how to answer questions. And then, participants completed questionnaires on their own. All questionnaires can be finished in $30 \mathrm{~min}$. After completing questionnaires, participants handed them to researchers directly.

\subsection{Instruments}

\subsubsection{Short-form UCLA Loneliness scale (ULS-8)}

This short-form UCLA Loneliness scale (ULS-8) contains the 8 items selected from the revised UCLA Loneliness Scale of Hays and DiMatteo (1987). The items were (a) I lack companionship, (b) There is no one I can turn to, (c) I am an outgoing person, (d) I feel left out, (e) I feel isolation from others, (f) I can find companionship when I want it, (g) I am unhappy being so withdrawn, and (h) People are around me but not with me. The study employed a 4-point Likert scale with values ranging from "never" to "always". In this study, the internal reliability of the ULS-8 was 0.84 .

\subsubsection{Satisfaction with Life Scale}

The Satisfaction with Life Scale (SWLS), developed by Diener, Emmons, Larsen, and Griffin (1985), is a widely used measure of subjective well-being. The scale contains 5 items and employs 
a 7-point Likert scale with higher values corresponding to a higher degree of satisfaction. The total score is calculated to represent the level of satisfaction, ranging from 5 to 35 . The internal reliability, test-retest reliability coefficients of the SWLS were generally higher than 0.80 across different reports (see Pavot \& Diener, 1993). Additionally, it has been shown that SWLS has only one-factor and adequate construct validity, convergent validity, and discriminant validity (e.g., Arrindell, Heesink, \& Feij, 1999; Lucas, Diener, \& Suh, 1996; Pavot \& Diener, 1993). Wu and Yao's study (2006) has also confirmed the single-factor structure of the SWLS-Taiwan version, and revealed the SWLS-Taiwan version was factor invariant across gender. In this study, the internal consistency (coefficient $\alpha$ ) of the scale was 0.89 .

\subsubsection{Social Support Questionnaire ( $S S Q$ )}

The Social Support Questionnaire (SSQ) was developed in this study to measure individuals' perception of the support they receive from their father, mother, siblings and friends. For each target, participants evaluate the support in three facets, including satisfaction, frequency, and have-want discrepancy. These three facets were widely used in evaluating individuals' social support (see McDowell \& Newell, 1996, chap. 4). For example, for father support, participants were asked, "Are you satisfied with the support you get from your father?", "How often do you gain support from your father?", and "Do you have enough support from your father?". Each item was evaluated on a 5-point Likert scale with values ranging from "not satisfied at all" to "extremely satisfied ", "never" to "always", or "not enough at all" to "more than enough" depending on the type of facet of the item. Although these three facets seemed to be related and quite similar, they still have differences in their meanings. First, the frequency measure is based on an individual's estimated times of receiving supports from others in a period of time. The have-want discrepancy measure is based on the comparison of supports they have with supports they want. This discrepancy measure takes a further step from the frequency measure. Finally, satisfaction measure is the affective consequence resulting from the have-want discrepancy (e.g., Higgins, 1987; Locke, 1969; Locke, 1976; Locker \& Dunt, 1978; Michalos, 1985). Hence, these three measures have different meanings in information processing. Exploratory factor analysis showed that there were four factors underlying the questionnaire: (a) father, (b) mother, (c) siblings, and (d) friends' support. The four factors had moderate correlations ranging from 0.27 to 0.43 . The internal consistency (coefficient $\alpha$ ) of the four target factors ranged from 0.73 to 0.87 . According to this result, an aggregated score for each target support was calculated by averaging the scores of its 3 items.

\subsubsection{Adult Attachment Scale Taiwan version (AAS-TW)}

The Adult Attachment Scale Taiwan version (AAS-TW) was revised from the Adult Attachment Scale (AAS, Collins \& Read, 1990) by Wu (2005) for measuring participants' attachment style. The AAS-TW has 10 items; participants scored each according to how characteristic the item was of them, using a 5-point Likert scale with values ranging from "not at all" to "very". There are two factors underlying the AAS-TW. The first factor is anxiety (4 items), which measures the extent to which an individual is anxious or fearful about abandonment or being unloved. The second factor is avoidance (6 items), which measures the extent to which an individual is uncomfortable with closeness and dependence on others emotionally close to them. In four different samples, the internal consistency (coefficient $\alpha$ ) ranged from 0.71 to 0.80 of the anxiety sub- 
scale and from 0.72 to 0.81 of the avoidant subscale (Wu, 2005). In Wu's (2005) study, results of exploratory and confirmatory factor analysis on different samples revealed that the two-factor structure was reliable and acceptable. In addition, anxiety and avoidance attachments were both negatively correlated with self-esteem, which is consistent with attachment theory (Bowlby, 1969) and other previous studies (e.g., Brennan \& Morris, 1997; Man \& Hamid, 1998; Roberts, Gotlib, $\&$ Kassel, 1996). In the current study, internal consistency of anxiety and avoidant subscales were 0.70 and 0.77 , respectively.

\subsection{Data analysis}

Confirmatory factor analysis with a covariance matrix was conducted using the CALIS procedure in the SAS system (SAS Institute Inc, 1999). In this model, the 8 items of the scale were explained by a single latent factor where factor variance was set to one and the unique variances of each item were uncorrelated. As an over-identification model, 36 data points with 16 parameters produced 20 degrees of freedom. The maximum likelihood method was used for model estimation, since Muthén and Kaplan (1985) suggest that if variables have skewness and kurtosis from -1 to +1 , then, estimating parameters for non-normal categorical variables with the maximum likelihood method was acceptable.

In addition, on the sample size of SEM or CFA analysis, Ding, Velicer, and Harlow (1995) note that 100-150 participants are sufficient to conduct SEM. Moreover, Bentler and Chou (1987) recommend that the ratio of sample size to number of free parameters be 5:1, though a ratio of 10:1 may be more appropriate. In the current model, there were 130 participants and the ratio of sample size to number of free parameters was nearly 8:1. According to the recommendations of Ding et al. (1995) and Bentler and Chou (1987), the sample size in this study was acceptable.

\section{Results}

\subsection{Confirmatory factor analysis of ULS-8}

Prior to confirmatory factor analysis, Table 1 presents the descriptive statistics of each item on the ULS-8, including the mean, standard deviation, skewness, and kurtosis.

Table 2 presents unstandardized and standardized estimates of the single-factor model. The parameters in the model were significant. Although the $\chi^{2}$ test rejected the model $\left(\chi^{2}(20)=36.13, p<.05\right)$, values of various fit indices were adequate $(\mathrm{NFI}=.90 ; \mathrm{NNFI}=.94$; $\mathrm{CFI}=.95 ; \mathrm{MFI}=.94 ; \mathrm{GFI}=.94 ; \mathrm{AGFI}=.89 ; \mathrm{RMSEA}=.08 ; \mathrm{RMR}=.03)$, suggesting that this single-factor model was acceptable. Generally, according to the overall information of the $\chi^{2}$ test, various fit indices, and parameter estimates, the model was acceptable.

However, the 2 items ("I am an outgoing person" and "People are around me but not with me") had lower factor loadings compared to other items. Comparing the content of the items, it was apparent that the content of these 2 items did not tap the meaning of isolation as much as the other 6 items. In order to see if these 2 items should be retained or deleted, a 6 -item model was analyzed. The parameters of the 6-item model were all significant. The $\chi^{2}$ test retained the model $\left(\chi^{2}(9)=12.14, p>.05\right)$, and values of various fit indices were also excellent $(\mathrm{NFI}=.96$; 
Table 1

Descriptive statistics of each item of ULS-8

\begin{tabular}{|c|c|c|c|c|}
\hline & Mean & $\mathrm{SD}$ & Skewness & Kurtosis \\
\hline I lack companionship & 2.12 & .78 & .38 & -.11 \\
\hline There is no one I can turn to & 1.96 & .71 & .45 & .26 \\
\hline I am an outgoing person ${ }^{\mathrm{a}}$ & 2.12 & .75 & .58 & .42 \\
\hline I feel left out & 2.27 & .76 & .17 & -.26 \\
\hline I feel isolation from others & 2.33 & .70 & .28 & .03 \\
\hline I can find companionship when I want it $^{\mathrm{a}}$ & 1.77 & .62 & .39 & .44 \\
\hline I am unhappy being so withdrawn & 2.05 & .78 & .50 & .06 \\
\hline People are around me but not with me & 2.50 & .82 & -.39 & -.49 \\
\hline
\end{tabular}

${ }^{\text {a }}$ Scores of reversed items have been recorded.

Table 2

Unstandardized and standardized estimates of the single-factor model

\begin{tabular}{|c|c|c|c|c|}
\hline \multirow[t]{3}{*}{ Items } & \multicolumn{4}{|c|}{$\underline{\text { Parameters }}$} \\
\hline & \multicolumn{2}{|c|}{ Unstandardized estimates } & \multicolumn{2}{|c|}{ Standardized estimates } \\
\hline & Loading & Unique variance & Loading & Unique variance \\
\hline I lack companionship & .62 & .22 & .80 & .60 \\
\hline There is no one I can turn to & .58 & .17 & .81 & .58 \\
\hline I am an outgoing person & .33 & .46 & .44 & .90 \\
\hline I feel left out & .43 & .39 & .57 & .82 \\
\hline I feel isolation from others & .50 & .24 & .71 & .70 \\
\hline I can find companionship when I want it & .39 & .22 & .64 & .77 \\
\hline I am unhappy being so withdrawn & .52 & .34 & 67 & .74 \\
\hline People are around me but not with me & .36 & .54 & .44 & .90 \\
\hline
\end{tabular}

Note. Scores of reversed items have been recorded.

Table 3

Correlations among variables for total sample

\begin{tabular}{|c|c|c|c|c|c|c|c|c|}
\hline & 1 & 2 & 3 & 4 & 5 & 6 & 7 & 8 \\
\hline 1. ULS-8 & - & & & & & & & \\
\hline 2. SWLS & $-.51^{* *}$ & - & & & & & & \\
\hline 3. Father support & $-.24^{* *}$ & $.28^{* *}$ & - & & & & & \\
\hline 4. Mother support & $-.27^{* *}$ & $.29^{* *}$ & $.32^{* *}$ & - & & & & \\
\hline 5. Sibling support & $-.27^{* *}$ & $.41^{* *}$ & $.48^{* *}$ & $.37^{* *}$ & - & & & \\
\hline 6. Friend support & $-.50^{* *}$ & $.30^{* *}$ & $.25^{* *}$ & $.23^{* *}$ & $.29^{* *}$ & - & & \\
\hline 7. Anxiety & $.49^{* *}$ & $-.26^{* *}$ & $-.26^{* *}$ & -.04 & -.12 & $-.35^{* *}$ & - & \\
\hline 8. Avoidant & $.48^{* *}$ & $-.27^{* *}$ & -.15 & $-.25^{* *}$ & -.17 & $-.27^{* *}$ & $.29^{* *}$ & - \\
\hline
\end{tabular}

Note. The correlations involving sibling support were based on 119 participants' data in total sample, because some participants did not have siblings.

$p<0.01$. 
$\mathrm{NNFI}=.98 ; \mathrm{CFI}=.99 ; \mathrm{MFI}=.98 ; \mathrm{GFI}=.97 ; \mathrm{AGFI}=.93 ; \mathrm{RMSEA}=.05 ; \mathrm{RMR}=.02) . \mathrm{It}$ seemed that the 6-item model was better than the 8 -item model. However, a $\chi^{2}$ difference test between the 6-item and the 8-item model was significant $\left(\chi^{2}(11)=23.99, p>.05\right)$, showing that these two models were different. In other words, parameters of these 2 items in the 8 -item model cannot just be treated as non-significant and deleted directly.

\subsection{Correlation analysis between ULS-8 items and relevant variables}

In order to examine the validity of the ULS-8, its score was correlated with the SWLS, father support, mother support, sibling support, friend support, anxiety attachment, and avoidant attachment scores. Table 3 presents the results of the correlation analyses among all variables. The ULS-8 was negatively correlated with the SWLS, father support, mother support, sibling support, and friend support, and positively correlated with anxiety and avoidant attachment.

\section{Discussion}

The UCLA Loneliness Scale is a widely used measure of loneliness. In this study, by validating a short-form UCLA Loneliness Scale (ULS-8) in Taiwan we can show that the ULS-8 is an adequate short-form measure of loneliness. On the confirmatory factor analysis result, the one-factor model with substantial loadings on each item reveals that the 8 items are homogeneous when measuring loneliness. Although 2 items ("I am an outgoing person" and "People are around me but not with me") have lower factor loadings and seem to tap a different meaning from the other items, we still think the one-factor model is suitable for the ULS-8. It is because (1) items from different aspects are valuable in defining loneliness as a comprehensive construct, (2) a model comparison between the 6-item model and the 8-item model suggests that parameters of these 2 items in the 8-item model cannot simply be regarded as non-significant, (3) although the 8-item model is not as excellent as the 6-item model, the values of fit indices of the 8-item model are still adequate and acceptable. Therefore, we recommend the use of the 8 items, rather than the 6 items.

On the validity, the ULS-8 has hypothetical relations with the SWLS, social support, and adult attachment tendency, suggesting the ULS-8 has good validity. However, it is interesting that the ULS-8 had a stronger relationship with friend support than family support - father support, mother support, and sibling support. It may be because the sample of this study is university students and, at this stage in their lives, friends are more important to them than family (Wilks, 1986). Consequently, the relation between the ULS-8 and friend support appears stronger than that of family support. Although this is a reasonable explanation, a further investigation is still needed.

Overall, results of this study indicate that the ULS-8 is an acceptable loneliness measure. However, several limitations should be mentioned. First, the sample size in the current study was small and participants were only undergraduate students. Although this sample size was adequate to conduct a confirmatory factor analysis, however, it was not representative enough to demonstrate that the ULS- 8 can be administered on different populations. Thus, to be conservative, we only conclude that the ULS-8 is an adequate measure of loneliness for university students. 
Second, the criterion measures used in this study were self-report scales. The significant correlations between the ULS-8 and criterion variables would result from the common-method effect. Although the significant results may not totally be attributed to the common-method effect, it is more desirable to investigate the validity of the ULS-8 using criterion measures assessed by other methods, such as behavior coding, observer rating, or other self-report loneliness measures with different operational definitions (such as the Loneliness Rating Scale, Scalise, Ginter, \& Gerstein, 1984), etc. In addition, loneliness-related psychopathological constructs such as depression and anxiety, are also worth incorporating in future studies as well.

Third, the criterion variables used in this study were the constructs that were closely related to loneliness, because this study was aimed to show the ULS-8 is an adequate measure of loneliness, not to examine or explore the psychological mechanism of loneliness. As a result, the scope of this study is restrictive without providing theoretical contributions to loneliness studies. In conclusion, the current study revealed that ULS-8 is an adequate measure of loneliness in the Taiwan student sample.

\section{Acknowledgements}

This study was supported by National Science Council (NSC 92-2320-B-002-172). We also acknowledge Cheryl Sheridan for her comments on the manuscript.

\section{References}

Arrindell, W. A., Heesink, J., \& Feij, J. A. (1999). The Satisfaction with Life Scale (SWLS): Appraisal with 1700 healthy young adults in The Netherlands. Personality and Individual Differences, 26, 815-826.

Bentler, P. M., \& Chou, C. (1987). Practical issues in structural modeling. Sociological Methods and Research, 16, 78-117.

Bowlby, J. (1969). Attachment and loss: Vol. 1 attachment. New York: Basic Books.

Brennan, K. A., \& Morris, K. A. (1997). Attachment styles, self-esteem, and patterns of seeking feedback from romantic partners. Personality and Social Psychology Bulletin, 23, 23-31.

Cacioppo, J. T., Hawkley, L. C., Crawford, E., Ernst, J. M., Burleson, M. H., Kowalewski, R. B., Malarkey, W. B., Van Cauter, E., \& Berntson, G. G. (2002). Loneliness and health: Potential mechanisms. Psychosomatic Medicine, 64, 407-417.

Collins, N. L., \& Read, S. J. (1990). Adult attachment, working models, and relationship quality in dating couples. Journal of Personality and Social Psychology, 58, 644-663.

Davis, M. H., Morris, M. M., \& Kraus, L. A. (1998). Relationship-specific and global perceptions of social support: Associations with well-being and attachment. Journal of Personality and Social Psychology, 74, 468-481.

Diener, E., Emmons, R. A., Larsen, R. J., \& Griffin, S. (1985). The satisfaction with life scale. Journal of Personality Assessment, 49, 71-75.

Ding, L., Velicer, W. F., \& Harlow, L. L. (1995). Effects of estimation methods, number of indicators per factor, and improper solutions on structural equation modeling fit indices. Structural Equation Modeling, 2, 119-143.

DiTommaso, E., Brannen, C., \& Best, L. A. (2004). Measurement and validity characteristics of the short version of the social and emotional loneliness scale for adults. Educational and Psychological Measurement, 64, 99-119.

DiTommaso, E., Brannen-McNulty, C., Ross, L. R., \& Burgess, M. (2003). Attachment styles, social skills and loneliness in young adults. Personality and Individual Differences, 35, 303-312. 
Florian, V., Mikulincer, M., \& Bucholtz, I. (1995). Effects of adult attachment style on the perception and search for social support. Journal of Psychology, 129, 665-676.

Goodwin, R., Cook, O., \& Yung, Y. (2001). Loneliness and life satisfaction among three cultural groups. Personal Relationships, 8, 225-230.

Hays, R. D., \& DiMatteo, M. R. (1987). A short-form measure of loneliness. Journal of Personality Assessment, 51, 69-81.

Higgins, E. T. (1987). Self-discrepancy: A theory relating self and affect. Psychological Review, 94, 319-340.

Jackson, T., Fritch, A., Nagasaka, T., \& Gunderson, J. (2002). Towards explaining the association between shyness and loneliness: A path analysis with American college students. Social Behavior and Personality, 30, 263-270.

Jones, W. H., Rose, J. A., \& Russell, D. (1990). Loneliness and social anxiety. In H. Leitenberg (Ed.), Handbook of social and evaluation anxiety (pp. 247-266). New York: Plenum.

Kahn, J. H., Hessling, R. M., \& Russell, D. W. (2003). Social support, health, and well being among the elderly: What is the role of negative affectivity?. Personality and Individual Differences 35, 5-17.

Locke, E. A. (1969). What is job satisfaction? Organizational Behavior and Human Performance, 4, 309-336.

Locke, E. A. (1976). The nature and causes of job satisfaction. In M. D. Dunnette (Ed.), Handbook of Industrial and Organizational Psychology (pp. 1297-1343). Chicago: Rand McNally.

Locker, D., \& Dunt, D. (1978). Theoretical and methodological issues in sociological studies of consumer satisfaction with medical care. Social Science and Medicine, 12, 283-292.

Lucas, R. E., Diener, E., \& Suh, E. (1996). Discriminant validity of well-being measures. Journal of Personality and Social Psychology, 71, 616-628.

Man, K. O., \& Hamid, P. N. (1998). The relationship between attachment prototypes, self-esteem, loneliness and causal attributions in Chinese trainee teachers. Personality and Individual Difference, 24, 357-371.

McDowell, I., \& Newell, C. (1996). Measuring health: A guide to rating scales and questionnaires (2nd ed.). New York: Oxford University Press.

Michalos, A. C. (1985). Multiple discrepancies theory (MDT). Social Indicators Research, 16, 347-413.

Moody, E. J. (2001). Internet use and its relationship to loneliness. CyberPsychology and Behaviour, 4, 393-401.

Morahan-Martin, J. (1999). The relationship between loneliness and Internet use and abuse. CyberPsychology and Behavior, 2, 431-440.

Muthén, B., \& Kaplan, D. (1985). A comparison of some methodologies for the factor analysis of non-normal Likert variables. British Journal of Mathematical and Statistical Psychology, 38, 171-189.

Neto, F. (1995). Predictors of satisfaction with life among second-generation migrants. Social Indicators Research, 35 , 93-116.

Pavot, W., \& Diener, E. (1993). Review of the satisfaction with life scale. Psychological Assessment, 5, 164-172.

Peplau, L. A., \& Perlman, D. (1982). Loneliness: A sourcebook of current theory research and therapy. New York: Wiley.

Roberts, J. E., Gotlib, I. H., \& Kassel, J. D. (1996). Adult attachment security and symptoms of depression: The mediating roles of dysfunctional attitudes and low self-esteem. Journal of Personality and Social Psychology, 70, 310-320.

Russell, D. (1996). UCLA Loneliness Scale (version 3): Reliability, validity, and factor structure. Journal of Personality Assessment, 66, 20-40.

Russell, D., Peplau, L. A., \& Cutrona, C. E. (1980). The revised UCLA Loneliness Scale: Concurrent and discriminant validity evidence. Journal of Personality and Social Psychology, 39, 472-480.

Russell, D., Peplau, L. A., \& Ferguson, M. L. (1978). Developing a measure of loneliness. Journal of Personality Assessment, 42, 290-294.

SAS Institute Inc. (1999). SAS language reference: Concepts, version 8. Cary, NC: SAS Institute Inc.

Scalise, J. J., Ginter, E. J., \& Gerstein, L. H. (1984). A multidimensional loneliness measure: The loneliness rating scale (LRS). Journal of Personality Assessment, 48, 525-530.

Solomon, Z., Waysman, M., \& Mikulincer, M. (1990). Family functioning, perceived societal support, and combatrelated psychopathology: The moderating role of loneliness. Journal of Social and Clinical Psychology, 9, 456-472.

Weiss, R. S. (1973). Loneliness: The experience of emotional and social isolation. Cambridge, MA: MIT Press.

Wilks, J. (1986). The relative importance of parents and friends in adolescent decision-making. Journal of Youth and Adolescence, 15, 323-334. 
Wilson, D., Cutts, J., Lees, I., Mapungwana, S., \& Maunganidze, L. (1992). Psychometric properties of the revised UCLA loneliness scale and two short-form measures of loneliness in Zimbabwe. Journal of Personality Assessment, 59, 72-81.

Wiseman, H., Guttfreund, D. G., \& Lurie, I. (1995). Gender differences in loneliness and depression of university students seeking counseling. British Journal of Guidance and Counselling, 23, 231-243.

Wu, C. H. (2005). Factor analysis of the Adult Attachment Scale-Taiwan version. Poster presented at the 44th annual conference of Taiwanese Psychological Association, Tau-Yuan, Taiwan.

$\mathrm{Wu}$, C. H., \& Yao, G. (2006). Analysis of factorial invariance across gender in the Taiwan version of the Satisfaction with Life Scale. Personality and Individual Differences, 40, 1259-1268. 